\title{
Cuatro personajes en busca de sí mismos. Análisis comparativo de la presencia y consecuencias de la guerra en la novela y en la película El paciente inglés
}

\section{Four characters looking for themselves. Comparative analysis of the presence and consequences of war in the novel and film The English Patient}

\author{
SOFía MALVIDO CORDEIRO \\ Universidade de Vigo \\ smalvido@uvigo.es \\ ORCID ID: 0000-0002-3307-6680
}

Resumen: En este artículo se realiza un análisis comparativo entre la novela de Michael Ondaatje El paciente inglés y la adaptación cinematográfica homónima de la mano del director Anthony Minghella, prestando especial atención a aquellos aspectos relativos a la guerra y las consecuencias con las que el conflicto bélico marca a los cuatro protagonistas de esta historia.

Palabras clave: cine, literatura, comparatismo, guerra, El paciente inglés.

\begin{abstract}
In this article a comparative analisis is made between Michael Ondaatje's novel The English Patient and homonymous film adaptation directed by Anthony Minghella. This study analyses the presence of war and how the four main characters deal with its consequences.
\end{abstract}

Keywords: film, literature, comparatism, war, The English Patient. 


\section{INTRODUCCIÓN}

Adaptar, trasladar, recrear, transponer o reescribir son algunas de las denominaciones dadas al ejercicio de explorar de nuevo una obra en un lenguaje distinto de aquel en el que fue creada originariamente (Helbo, 1997: 25). Los tipos de análisis en los que uno de los términos de la comparación rebasa las fronteras de la literatura, y que han venido a llamarse Estudios Interartísticos, son relativamente recientes, si bien se cuenta ya con un volumen importante de monografías e investigaciones especializadas dedicadas a tales temas. Entre ellas, el libro de José Luis Sánchez Noriega, De la literatura al cine (2000), ha sido una de las guías fundamentales utilizadas en el presente artículo.

Respecto al acercamiento crítico en las relaciones específicas entre literatura y cine, cada investigador se ha valido de las teorías y procedimientos propios de las disciplinas implicadas, de modo que, a pesar de trabajar en un terreno fronterizo, no hemos desechado los métodos proporcionados por la Historia de la Literatura y del Cine, ni, como es obvio, por aquellos aportados por la Narratología y los Estudios Fílmicos, que nos han suministrado recursos imprescindibles para el estudio de cada uno de los términos de la comparación por separado.

Para iniciar este análisis, tomaré como referencia la novela El paciente inglés $\mathrm{y}$, a través del desarrollo del argumento, iré desgranando las características principales que presenta el modo de narrar la historia, lo cual facilitará el entendimiento de los procesos específicos que serán necesarios para trasponer las imágenes narradas al lenguaje fílmico.

\section{Personajes de la novela}

Al término de la Segunda Guerra Mundial, cuatro personajes conviven en una villa italiana en ruinas. Hana es una enfermera que ha perdido cuanto quiso y se aferra a velar por su paciente, casi totalmente quemado y sin identidad, más allá de su origen inglés. Caravaggio es un ladrón que tomó parte del bando inglés y lo pagó con sus pulgares, por lo cual habita en el universo de la morfina y los recuerdos. Por último, Kip es un especialista en desactivación de explosivos indio que encontrará mucho más de lo que esperaba en ese lugar.

Alrededor de la cama del paciente inglés se van a ir gestando unos lazos necesarios para que cada uno pueda tomar su propio rumbo: el paciente dejará atrás su pasado como amante de una mujer y del desierto; Hana se entregará, sin saberlo, a algo más que fantasmas; Kip encontrará sus raíces y formará un futuro en la India; y Caravaggio se sumirá en las sombras de la villa. 
A pesar de no ser una novela muy dialogada, la interacción entre los personajes cumple una función primordial. El diálogo entre Caravaggio y Almásy, nombre del paciente, guiado por los efectos de la morfina, trae al tiempo de la historia los recuerdos adormecidos del paciente inglés, trasladándonos al desierto y creando, así, saltos continuados en la temporalidad de la historia. Ya antes, en sus propias divagaciones, se habían presentado los espacios y personajes que los componen, pero no es hasta este momento cuando se ordenan los recuerdos por el incansable interrogatorio del italiano.

Derivado de la utilización del narrador omnisciente en tercera persona, el lector tiene acceso a la psicología de los personajes más allá de lo que traslucen sus intervenciones directas. Se trata de personalidades poliédricas que evolucionan a lo largo de la historia, complejidad que está reflejada en sus pensamientos. Todos los personajes van transformándose frente al lector por medio de los diálogos y a lo largo de la convivencia en la villa italiana. Entre otros ejemplos que constatan la afirmación anterior citaremos el efecto que genera en Hana hablar de su pasado con Caravaggio; la paz que proporciona al paciente inglés poder armar las piezas de su identidad mediante el relato de sus vivencias; el vínculo entre Kip y el paciente por tener intereses comunes: «Creo que ha encontrado a un amigo", dijo Hana a Caravaggio [al verlos hablar]» (Ondaatje, 1995: 105). Pero, al mismo tiempo, su introspección es un diálogo que se establece con ellos mismos, en el cual cuestionan, vaticinan y recrean todo un universo psicológico.

La mayoría de los sucesos narrados se desarrollan en la Villa San Girolamo (al norte de Florencia) y el desierto de Gilf Kebir. En contraposición con aquellos espacios cuya función se limita a proporcionar a la acción un lugar físico donde desarrollarse, como es el caso de Inglaterra, otros van más allá de esa función adquiriendo trascendencia semántica; pensamos por ejemplo en la Capilla Sixtina (Ondaatje, 1995: 92) o en la casa donde capturan a Caravaggio, Villa Cosima (1995: 47-52):

Un libro, un mapa de nudos, un tablero con espoletas, una habitación con cuatro personas en una villa abandonada e iluminada sólo por velas y de vez en cuando los destellos de los relámpagos o el posible resplandor de una explosión. Las montañas, las colinas y Florencia a ciegas, sin electricidad. La luz de las velas no llega más allá de cincuenta metros. Desde una distancia mayor nada había allí que perteneciera al mundo exterior (1995: 129).

La descripción anterior traduce la atmósfera en la que se mueven los cuatro personajes. A pesar de ser un momento feliz para todos, 
un punto de inflexión en la novela, la oscuridad no deja de cernirse sobre ellos, como una pesada carga que no se solventa en una noche. El siguiente ejemplo que proponemos es una descripción más apegada a su estructura física del lugar descrito, pero sin dejar de lado el lirismo característico de esta novela:

La Villa San Girolamo, construida para proteger a los habitantes de la diabólica carne, tenía el aspecto de una fortaleza asediada y los bombardeos de los primeros días habían arrancado las extremidades a la mayoría de sus estatuas. Apenas parecía haber línea divisoria entre la casa y el paisaje, entre el edificio dañado y los restos, quemados y bombardeados, de la tierra. Para Hana, los jardines, invadidos por la vegetación, eran como otros cuartos de la casa. Trabajaba en sus lindes, atenta siempre a las minas sin estallar. En una zona de suelo fértil contigua a la casa, pese a la tierra quemada, pese a la falta de agua, se puso a cultivar con una pasión frenética que sólo podía asaltar a quien se hubiera criado en una ciudad. Un día habría una enramada de tilos, habitaciones de luz verde (2005: 55).

Como queda de manifiesto, la atmósfera que rodea a los personajes se presenta como un resquicio de esa guerra de la que tratan de huir, aislándose en la vieja villa.

\section{Personajes de la película}

Ahora, en contraposición, veremos cómo, ya desde el argumento de la obra cinematográfica, las divergencias entre los dos géneros narrativos se hacen patentes partiendo de la naturaleza de los personajes, hasta la adecuación a un sistema estético concreto, como es el hollywoodiense.

Mientras la Segunda Guerra Mundial desangraba los mapas y remarcaba sus fronteras, en los hospitales de campaña del norte de Italia, una joven enfermera franco-canadiense lidiaba con las consecuencias del conflicto. Entre luces y sombras asiste a una deshumanización necesaria para hacer frente al horror, la suya propia.

Con todo perdido y sin dejar entrar en sí misma la esperanza del inminente fin de la contienda, decide refugiarse en un viejo monasterio en ruinas y convivir con el peligro de la detonación de las bombas que allí se albergan y la inestabilidad del momento. Junto a ella, y como excusa para este confinamiento, se encuentra uno de los pacientes que había atendido y del cual decide hacerse cargo, por la extrema gravedad de sus heridas, durante el tiempo que transcurra hasta su muerte. Los daños de este paciente van más allá de sus visibles quemaduras y la consiguiente desfiguración de su rostro; se encuentra desprovisto de memoria y sus recuerdos, oníricos y 
fugaces, son un torrente que turba su quietud. A causa de esta amnesia está despojado de su identidad y todos se refieren a él como "el paciente inglés", ya que su voz y acento británico son los únicos rasgos identificativos.

Recién comenzada esta nueva empresa que supuso instalarse en un lugar ruinoso y tratar de acomodar los pocos elementos que componen el mobiliario y la huerta de la villa, Hana se ve sorprendida por la llegada de un hombre llamado Caravaggio. Este es un ladrón que había servido de espía en el bando aliado y, como consecuencia de su implicación en una misión fallida, perdió los pulgares en el proceso de un interrogatorio llevado a cabo por el ejército nazi. Debido a los dolores sufre una severa adicción a la morfina, que se evidencia desde el primer momento por el robo continuado de este sedante, que Hana aprovisiona para el paciente. Desde su primera aparición se pone de manifiesto que es un ser atormentado que esconde un secreto que estará estrechamente relacionado con la verdadera identidad del paciente: László Almásy, un espía húngaro que había cartografiado el desierto para el ejército alemán y que está involucrado en las miserias sufridas por Caravaggio.

Pasado poco tiempo desde la llegada del nuevo huésped a la villa, aparece en escena Kip, un zapador sij, alistado en el ejército británico, que está encargado de desactivar las bombas que todavía no habían sido detonadas en el lugar. Debido a la dificultad de la empresa debe permanecer en la villa durante un tiempo, conviviendo con el resto de los personajes y forjando lazos importantes en el desarrollo de la historia. Entre él y Hana surgirá una relación pasional que mostrará su lado más vulnerable, junto con otras vivencias que lo marcarán hondamente. Y también llegará a congeniar con el paciente inglés por sus intereses comunes, que les llevarán a establecer largas conversaciones.

Paralelamente a este momento de la historia, en el cual estos tres personajes convivirán en la ermita reconvertida en refugio, el paciente, Almásy, irá desgranando los detalles de su pasado a través de sus recuerdos. Estas memorias, recreadas en la pantalla, darán luz a su identidad y descubrirán la historia de una pasión demoledora entre él y Katharine, la esposa de uno de sus compañeros de expedición. Esta historia de amor truncada es el eje a través del cual se vertebra su presente; es la causa de su amnesia, de las quemaduras que le cubren el cuerpo y de las hondas heridas que han quedado en su conciencia dormida. Será la causa final por la cual decidirá acabar con su vida, con la ayuda de Hana. 


\section{Tratamiento del belicismo en la NOVEla y la Película}

El comienzo de la película, con las imágenes de las pinturas de La Gruta de los Nadadores y el avión sobrevolando el desierto, adelantan la presencia de la aventura en la historia, impresión que se ve matizada por los disparos que sorprenden a la pareja que surca el cielo plácidamente; a simple vista parece una película bélica. Sin embargo, el conflicto queda de fondo desde el primer momento. A raíz de estos minutos iniciales, se formularán en la mente del espectador, inevitablemente, cuestiones sobre la escena que presencia, la identidad de los personajes y el estado de la mujer, aparentemente dormida. Este comienzo refleja la atmósfera que dominará todo el metraje; es decir, la guerra, el conflicto armado, está ahí para que no nos olvidemos de lo que atormenta y obliga a convivir a los personajes, pero es inevitable no dejar de lado, por un momento, la batalla externa y ahondar en la lucha interna que cada uno de ellos está librando. Esto está facilitado por la disposición de los momentos de tensión de la película. A medida que avanza la narración, las tramas amorosas y la psicología de los personajes se hacen con el centro de la atención del espectador. Es que esta es, en gran medida, una película sobre los efectos de la guerra en los individuos, no sobre el conflicto en sí mismo.

Como subraya en su acercamiento al cine bélico Ángel L. Hueso (1983: 17-19), se debe discernir entre cine histórico y cine bélico. Este último no implica solamente la presencia de una conflagración, sino que se centra en la relación de conflictos, generalmente del siglo $\mathrm{XX}$, y su repercusión en el hombre contemporáneo. Pero con el devenir del tiempo y el asentamiento del género, se han ido fijando algunos tópicos: uno referente a la ética, por ejemplo, en la configuración de buenos y malos en los bandos contendientes; y el otro a la tipología de los personajes, que se ven reducidos a un símbolo de alguno de estos valores éticos.

Dejando de lado el punto de vista, el enaltecimiento o la condena, desde el que se desea mostrar el conflicto bélico, existe una subcategorización que ayuda a perfilar las características que configuran este tipo de cine: documental, de propaganda, pacifista, de la resistencia y novelación. El caso de El paciente inglés, en cambio, diverge de los antes citados.

Si se sigue la estela del cine bélico a lo largo de estos últimos años, se aprecia que el foco de atención sobre la conflagración es mucho menor y aumenta, en cambio, el interés por los sujetos que viven o vivieron la guerra pero que no están inmersos en el conflicto, sino que se enfrentan a otras encrucijadas morales: Salvar al soldado Ryan (1998) de Steven Spielberg o Malditos Bastardos (2009) de Tarantino, son unos buenos ejemplos de esta nueva concepción. 
En la obra que nos ocupa, los cuatro habitantes de la Villa de San Girolamo tienen la guerra como fondo y fuerza que los ha guiado hasta ese momento. Son personajes fruto de la guerra, que la llevan consigo, atrapados por circunstancias ajenas en vidas que no eligieron. Como comentábamos anteriormente, su confinamiento físico en el espacio de la narración va de la mano de un aislamiento autoinfligido a nivel psicológico como respuesta a los traumas de la guerra y el sufrimiento que acarrean.

Cabe destacar también que en la película la guerra es un tema que está presente, puesto que el conflicto está aún desarrollándose y no será hasta la mitad de la cinta cuando se ponga fin al mismo; en la novela, en cambio, las tropas alemanas habían sido derrotadas en el territorio en un momento anterior a la llegada a la villa, dato proporcionado en un diálogo posterior entre Hana y Caravaggio. Esta es una de las muchas divergencias que encontramos al realizar un análisis entre las dos obras. Algunas de las diferencias vienen dadas por decisiones artísticas, pero otras están condicionadas por los medios en los que se crean.

\section{REAJUSTES AL SISTEMA HOLLYWOODIENSE}

La novela es descifrada gracias a la capacidad y la experiencia del lector, por tanto, puede estar ambientada en cualquier lugar o en cualquier tiempo, puede incluir en su trama a todo tipo de personajes, incluso a personajes históricos, al margen de que estén vivos o muertos en el momento de la lectura. En la novela, lo primordial es la imaginación activa del lector; siempre y cuando se presente de forma verosímil y coherente, de acuerdo con el pacto ficcional; no resulta complicado enfrascarse en su lectura e ir página a página apueblándose, con palabras de Ortega ${ }^{1}$, en la ficción, en el mismo espacio y tiempo que los personajes. Sin embargo, el cine, arte de naturaleza fundamentalmente visual, encuentra en ocasiones dificultades para lograr trasladar a la imagen determinados planteamientos que propone la novela de la que parte. Debemos tener en cuenta, asimismo, que en la década de los 90, cuando fue producida la película, no existía la libertad creativa que tantas veces proporcionan los efectos especiales de los que se dispone actualmente.

\footnotetext{
${ }^{1}$ Novelar es confinar al lector en un espacio cerrado. En palabras de Ortega, «la táctica del autor ha de consistir en aislar al lector de su horizonte real y aprisionarlo en un pequeño horizonte hermético e imaginario que es el ámbito interior de la novela». Esa táctica recibirá la denominación de apueblamiento (Ortega y Gasset, 1976: 200).
} 
A la hora de analizar una película, resulta interesante fijar la atención en aquellos cambios que se producen como respuesta a la adecuación a un sistema estético determinado. En este caso, y más teniendo en cuenta el referente literario del que parte, resulta evidente que la historia se adecúa a la estética hollywoodiense, no solo en la fotografía, sino también en el tratamiento de algunos de los temas tratados en la historia:

The closure at the end of a Hollywood film makes the world seem more just, predictable, logical, and often more hopeful than it is in fact. No wonder billions of people love Hollywood films. At the same time, if Hollywood conventions are adhered to too rigorously -if the characters are too predictable, the closure at the end too patHollywood movies can seem silly or empty, too obviously escapist.

The best Hollywood directors were able to exploit the intrinsic appeal of established Hollywood conventions while injecting original or personal elements into their films, adding something of themselves to give their films an edge. The films we value most not only calm and reassure us, but unsettle and challenge us too (Fabe, 2004: 72).

De acuerdo con lo expuesto en la cita anterior, extraída del ensayo Closely Watched Films: An Introduction to the Art of Narrative Film Technique, debemos puntualizar que, aun inscribiéndose en esta estética, Anthony Minghella hace un buen trabajo no rebasando los límites de la fidelidad con el fin de no caer, asimismo, en los clichés que acostumbramos a encontrarnos en estas narraciones. Y también es un hecho que, a pesar del atisbo de esperanza final, su puesta en escena es notablemente más oscura de lo acostumbrado.

La estética o ideología hollywoodiense es fácilmente reconocible, ya que estamos cada vez más embebidos en este universo de happy endings y luces por doquier. La cartelera actual y nuestras pantallas se encuentran dominadas por películas prefabricadas con modelos que resultan familiares al espectador, ya sea por su estructura, planteamientos, temática o recursos estéticos. Hollywood es una industria que necesita producir y recaudar, cuanto más mejor, dejando de lado, o cuando menos en un lugar irrelevante, la calidad de estos productos. Por esta razón, nos encontramos cada vez más frecuentemente con "películas de consumo rápido" que no dejan traslucir el verdadero trasfondo de los personajes, más allá de obedecer a un estereotipo que facilita el entendimiento de una realidad demasiado compleja para tener cabida en moldes prefijados ${ }^{2}$.

2 Para profundizar sobre el cine en la era moderna y la industria
cinematográfica hollywoodiense reciente, resulta especialmente interesante 
En el caso concreto de El paciente inglés, la adaptación a esta estética hollywoodiense se traduce en una menor profundidad de los personajes de forma general, mayor luminosidad en la escena y una edulcoración de motivos, sobre todo al término de la película.

El pasado de Hana, Caravaggio y Kip se transforma en su paso al medio fílmico en un mero apunte, un condicionante que asegure la empatía del espectador. Sin embargo, en la novela se conocen luces y sombras de unos y otros, sus luchas internas, sus controvertidos actos respecto a la moral impuesta, como es el caso de los sentimientos de Hana respecto a su aborto provocado, unido a la muerte de su novio:

Perdí el niño. Quiero decir que hube de perderlo. El padre ya había muerto. Estábamos en guerra [...]. Conversaba sin cesar con el niño. Trabajaba denodadamente en los hospitales y me aparté de todos los que me rodeaban, excepto el niño, con el que lo compartía todo: en mi cabeza. Hablaba con él mientras bañaba y cuidaba a los pacientes. Estaba un poco loca (Ondaatje, 1995: 9697).

Salí con un hombre que murió y el niño murió. La verdad es que el niño no murió precisamente, sino que acabé yo con él. Después de aquello, me retraje tanto, que nadie podía acercárseme (1995: 100).

También en la novela, como adelantaba, las menciones a la oscuridad son continuas, y aunque en el proceso de transposición se intenta conservar en muchas escenas este mundo de sombras que reina en la Villa de San Girolamo (hasta diecinueve veces aparecen nombradas en el guion), muchas otras, en cambio, se nutren de esta estética hollywoodiense que da un barniz esperanzador al futuro de los personajes. De este modo ocurre con las últimas imágenes de Hana en el film: vemos cómo se aleja, sentada en la parte de atrás de un vehículo, mirando hacia la villa con una gran sonrisa de despedida. Algo totalmente diferente sucede en la novela, donde la historia finaliza con la joven enfermera cuidando todavía del paciente, sin mención alguna a la eutanasia que termina con la vida de Almásy en la película.

En general, en la trasposición entre los dos medios, los personajes se ven alterados, bien en elementos circunstanciales, bien en partes fundamentales de su personalidad, lo cual no está necesariamente vinculado a la estética, sino que puede ser un modo de representar la

consultar los estudios de Gilles Lipovetsky, en particular La pantalla global. Cultura mediática y cine en la era hipermoderna (Lipovetsky y Serroy, 2009), así como la obra reciente La crisis de valores en el cine posmoderno (Imbert, 2019). 
lectura de la obra por parte del director o el modo de representarlo por parte de los actores.

En cuanto a Hana, las modificaciones no pervierten las raíces del personaje, pero sí que alteran ciertos aspectos fundamentales para entender su presente y su persistente oscuridad. Por otra parte, es necesario advertir que en su paso al film la protagonista de la novela se ve desplazada en este puesto por el paciente inglés, quien, tanto en su etapa en la villa como en su pasado como cartógrafo, va relegando a Hana a un segundo plano a medida que avanza la historia.

Veamos algunas de esas modificaciones: se eliminan, como indicaba al inicio, las referencias al aborto de Hana, aunque sí se incluye la muerte de su pareja en el frente. También se elimina a Clara, madrastra de la joven enfermera y a quien escribe hacia el final de la historia para hablar de su padre, Patrick. En esta carta, Hana reflexiona sobre la muerte de su padre en un palomar, después de ser abandonado por los soldados de su regimiento, y sobre la imposibilidad de haberlo ayudado, partiendo de su labor como enfermera de guerra:

Era un hombre quemado y yo era enfermera y habría podido cuidarlo. ¿Entiendes la tristeza que entraña la geografía? Podría haberlo salvado o al menos haber permanecido con él hasta el final. Sé mucho sobre quemaduras. ¿Cuánto tiempo permanecería a solas con las palomas y las ratas, en las últimas fases de la sangre y la vida, con palomas por encima de él, revoloteando a su alrededor, sin posibilidad de dormir en la obscuridad, que siempre había detestado, y solo, sin la compañía de una amante o un familiar? (Ondaatje, 1995: 323, en cursiva en el original).

El hecho de que reflexione de este modo sobre las quemaduras y la imposibilidad de ayudarle a la que hubo de enfrentarse, posiblemente dan la clave de por qué decidió quedarse con el paciente inglés. En la novela, Hana también le dice al paciente que su padre está en la guerra (1995: 54), dando cuenta, quizás, de que para ella su recuerdo se quedó paralizado en ese momento del conflicto. De nuevo se pierde un matiz significativo en la presentación de los personajes, que, aunque pueda ser un modo de acortar el metraje, dice mucho más de su psicología que otros elementos conservados o añadidos a la adaptación.

Por otro lado, y siguiendo con las alteraciones sufridas por el personaje de Hana, El peso argumental de la película se centra en dos parejas: Hana-Almásy y Katharine-Almásy, en detrimento de Kip y Caravaggio, que pierden profundidad y se ven relegados a un papel secundario. Debido a la importancia del romance entre Katharine y Almásy en la película, se incluyen muchas vivencias y elementos fruto de esta reelaboración argumental: encuentros y diálogos en los 
descansos de sus expediciones, y la célebre carta final de Katharine en la Gruta de los Nadadores:

Amor mío, te sigo esperando. Cuánto dura un día en la oscuridad... ¿Una semana? El fuego se ha apagado y empiezo a sentir un frío espantoso. Debería arrastrarme al exterior, pero entonces me abrasaría el sol. Temo malgastar la luz mirando las pinturas y escribiendo estas palabras. Morimos, morimos, morimos ricos en amantes y tribus y sabores que degustamos en cuerpos en que nos sumergimos como si nadáramos en un río. Miedos en los que nos escondimos como esta triste gruta. Quiero todas esas marcas en mi cuerpo. Nosotros somos los países auténticos, no las fronteras marcadas en los mapas con los nombres de hombres poderosos. Sé que vendrás y me llevarás al palacio de los vientos. Solo eso he deseado, recorrer un lugar como ese contigo. Con nuestros amigos, una tierra sin mapas. La lámpara se ha apagado y estoy escribiendo a oscuras.

Del mismo modo, los encuentros entre Hana y Kip pierden sutileza al plasmarse en imágenes obviando así parte de su trasfondo; es decir, la pasión arrastra consigo las significaciones asociadas a su común búsqueda de humanidad, de volver a sentirse personas del mundo y no hijos de la guerra.

El personaje de Kip pierde importancia en la versión fílmica y su personalidad también se ve alterada ligeramente. Frente al zapador comedido, racional y meditativo de la novela, la película presenta a alguien reservado pero pasional que abandona las reservas, que muestra en la novela, a dejar de lado su misión para centrarse en Hana. Asimismo, en la película desconocemos la mayoría de los detalles de su pasado, por los cuales se ve hondamente influido en la novela y, también, su futuro familiar y profesional que darán término a la historia en la obra literaria.

En cierto modo, en la novela, Kip termina siendo un personaje tan importante como Hana o el paciente inglés. Un personaje poliédrico y dueño de acciones que responden exactamente a los datos que de él se nos ofrecen en el texto. Es una persona comprometida que no sigue los dictámenes que se le imponen, sino que explora su propio camino. Por esta razón renuncia a ser médico, como le corresponde en su familia, y decide colaborar como zapador en la desactivación de bombas. En consonancia con su sentido de la responsabilidad, en la novela se describe su turbación al conocer los ataques de Nagasaki e Hiroshima, por parte de Estados Unidos, que serán la causa de su marcha. Esta actitud respecto a la situación es una muestra de que el personaje se resiste a perder su humanidad, que todavía albergaba esperanzas respeto a la bondad del hombre, incluso 
después del proceso bélico; pero esas esperanzas se ven frustradas por el atroz acto cometido. En la película, en cambio, sustituyen este importante acontecimiento por la muerte de su compañero zapador, que, si bien puede ser la gota que colme el vaso de todas las pérdidas que ha sufrido, no aporta la misma significación que el suceso de la novela.

Por otro lado, en la adaptación de la relación pasional que mantienen Kip y Hana se pierde el carácter independiente de estas dos personas atormentadas que encuentran un refugio en el cuerpo del otro. De hecho, Hana, descrita en ocasiones como vista a través de un agujero de su conciencia, busca en el diccionario la palabra comprometido (Ondaatje, 1995: 146) a la vez que el narrador acerca al lector las reflexiones sobre la libertad en su relación:

No sabemos hasta qué punto estaba enamorada ella de él o él de ella o hasta qué punto se trataba de un juego de secretos. A medida que intimaban, aumentaba el espacio que los separaba durante el día. A ella le gustaba la distancia que él le dejaba, el espacio que a su juicio le correspondía (1995: 145).

Más adelante Hana iba a comprender que ni él ni ella habían accedido a verse comprometidos el uno para el otro. Vería esa palabra en una novela, la sacaría del libro e iría consultarla en un diccionario. Comprometido: que ha contraído un compromiso u obligación. Y él no había accedido -y Hana lo sabía- a eso (1995: 146).

El personaje de Caravaggio es, sin duda, el que más difiere en su paso a la versión cinematográfica. En la obra literaria no se niegan sus defectos, ni su pasado y motivaciones, pero, aun así, no deja de ser un personaje entrañable y ocurrente, el encargado de llevar a la villa el momento de mayor felicidad con el robo del gramófono (1995: 124-133). En la novela es una pieza que liga a Hana con su pasado y sus vivencias, y es así como vamos conociendo más datos de ella y su familia. Como ella misma destaca, durante la guerra había necesitado a «un tío, a un miembro de la familia» (1995: 99), y la llegada de Caravaggio le proporcionó un enlace con su pasado y a alguien que está en el mismo plano que ella; a diferencia del paciente que está inmerso en sus recuerdos, con él puede hablar y rememorar. Una muestra de la unión entre estos dos personajes se representa mediante la escritura de Hana en El último mohicano: en el interior del libro, como una confesión a sí misma, plasma que lo quiso.

En cambio, en la adaptación cinematográfica, Caravaggio se presenta como un ser muy oscuro, carcomido por su adicción y sin ningún tipo de vinculación con el resto de los personajes hasta su llegada a la villa, de modo que no comparte esos lazos que serán 
definitorios en la transición psicológica de Hana. En ambos casos, tanto en la película como en la novela, Caravaggio es adicto a la morfina y paulatinamente se va haciendo con los suministros que Hana guarda para el paciente. Además de para su uso personal, Caravaggio también utilizará la morfina para sonsacar información a Almásy sobre su identidad, aunque con un matiz diferente en cada una de las obras. Si bien en la novela lo impulsan la curiosidad y cierta animadversión por la colaboración del paciente con el ejército nazi, en la película lo mueve el odio, puesto que él tuvo parte de la culpa en que el espía perdiera sus pulgares al ser atrapado por los alemanes. Pero, en ambos casos, el ex-espía termina compadeciéndose con el relato de un hombre que perdió a su gran amor e hizo todo lo posible por cumplir su promesa de regresar con ella a toda costa.

Frente a estas modificaciones de los personajes, subsiste la llamativa transformación de uno de los pilares que sustentan la ideología de estos caracteres: su declarado antibelicismo.

Ya se han anticipado las razones de la marcha de Kip. El zapador estaba comprometido con salvar vidas en su labor de desactivación de minas, por lo que dejó de lado el futuro que estaba ante él en India y se formó y viajó allí donde fuera necesario. El lanzamiento de las bombas nucleares escapa a su comprensión y el hecho de que estuvieran atacando a un grupo étnico al que, por otra parte, él pertenecía, provoca su cólera contra el paciente, que ahora representa la opresión a la que habían sido sometidos:

He estado sentado aquí, al pie de esta cama escuchándote estos últimos meses, porque eras como un tío para mí. [...] Me crié en las tradiciones de mi país, pero después, más que nada, con las de $t u$ país, tu frágil isla blanca que con costumbres, modales, libros, prefectos y razón convirtió en cierto modo al resto del mundo. [...] Vosotros y después los americanos nos convertisteis con vuestras normas misioneras. Y soldados indios perdieron sus vidas como héroes para poder ser pukkah ${ }^{3}$. Hacíais la guerra como si estuvieses jugando al críquet. ¿Cómo pudisteis embaucarnos para participar en esto? (Ondaatje, 1995: 308-309).

A partir de este momento de revelación y profundo dolor, Kip toma la decisión de marcharse, alejarse de Europa y de todo lo que de ella le había deslumbrado, incluyendo a sus compañeros de vivencias en la Villa de San Girolamo.

\footnotetext{
${ }^{3}$ Soldados de primera clase.
} 
El omnipresente trauma que sufre Hana por la muerte que le rodea y a la cual nombra con asiduidad se ve atenuado en la película. Por ejemplo, se elimina el hecho de que duerma en una hamaca que era de un hombre muerto y que lo tenga presente (pág. 59). Para Caravaggio también la guerra ha sido traumática, ha perdido a su mujer, ha perdido los pulgares y con su adicción a la morfina su cordura y su vida oscilan en un mismo eje. En la novela, en un momento en que se encuentra drogado por este opiáceo, se suelta a hablar sobre cómo les afecta la guerra:

El problema de todos nosotros es que estamos donde no debemos. ¿Qué estamos haciendo en África, en Italia? ¿Qué hace Kip desactivando bombas en huertos, por el amor de Dios? ¿Qué hace participando en guerras inglesas? Un agricultor del frente occidental no puede podar un árbol sin destrozar la sierra. ¿Por qué? Por la cantidad de metralla que le metieron dentro en la última guerra. Hasta los árboles están cargados de enfermedades que hemos provocado. Los ejércitos te adoctrinan y te dejan aquí y se van a tomar por culo y a armar follón en otra parte, inky-dinky parlezvous? Deberíamos largarnos todos juntos. [...] Nadie es más mezquino que los ricos. Te lo digo yo. Pero tienen que seguir las normas de su putrefacto mundo civilizado. Declaran la guerra, tienen honor y no pueden marcharse. Pero vosotros dos, nosotros tres, somos libres. ¿Cuántos zapadores mueren? ¿Por qué no has muerto tú aún? No seas responsable. La suerte no es eterna (Ondaatje, 1995: 140-141).

\section{CONCLUSIONES}

En suma, estamos ante dos obras que, aunque comparten una historia, beben de diferentes fuentes y responden a motivaciones que divergen entre sí. Aun con todo, es indudable el valor artístico de las dos narraciones y el buen hacer, por un lado, de Michael Ondaatje al crear una historia tan personal como universal y, por otro, el de Anthony Minghella al rodar una película que, siendo comercial, no traiciona la esencia del referente del que parte ni pierde su fuerza narrativa en esta trasposición entre los dos medios. Estas afirmaciones, que a priori podrían juzgarse como puramente subjetivas, se ven constatadas por la gran acogida de público y crítica que tuvieron ambas obras y la vigencia de la historia narrada.

Los conflictos armados se siguen sucediendo, haciendo mella en nuestra capacidad de asombro; seguimos sumidos en las sombras de nuestro pasado, sin hallar una salida al horror que continúa imparable, allá lejos. Pero conviene recordar, aunque se nos niegue la memoria, que nosotros fuimos ellos y el allá era aquí. 
Como cada ocasión en que la tragedia golpea, buscamos lo inmediato, nos buscamos a nosotros entre los restos de lo que fuimos y el hoy. Hana, Caravaggio, Kip y el paciente se encontraban sumidos en la tragedia, la oscuridad, el horror de no ser dueños de los cambios que los golpearon y los enviaron a su presente, pero, poco a poco, a través de la narración, sabemos que subsiste en ellos una necesidad de contar, de buscar, de hallarse en esas ruinas que los componen; son cuatro personajes en busca de sí mismos. Finalmente, no todos alcanzan la meta de su búsqueda o son capaces de enfrentarse a los conflictos que esta supone, pero nos dejan a nosotros, lectores ávidos de imágenes y palabras, apueblados en sus ruinas y contraluces.

\section{BibliogRAFÍA CITADA}

Fabe, Marilyn (2004), Closely Watched Films: An Introduction to the Art of Narrative Film Technique, Berkeley, University of California Press.

Helbo, André (1997), L'adaptation. Du théâtre au cinéma, París, Armand Collin.

HuEso, Ángel Luis (1983), Los géneros cinematográficos (Materiales Bibliográficos y Filmográficos), Bilbao, Mensajero.

IMBERT, G. (2019), La crisis de valores en el cine posmoderno, Madrid, Cátedra.

LipovetSKy, Gilles y Jean Serroy (2009), La pantalla global. Cultura mediática y cine en la era hipermoderna, Barcelona, Anagrama.

OndaAtje, Michael (1995), El paciente inglés, Barcelona, Plaza y Janés.

Ortega y Gasset, José (1976), Meditaciones del Quijote/Ideas sobre la novela, Madrid, Espasa-Calpe.

SÁnchez Noriega, José Luis (2000), De la literatura al cine. Teoría y análisis de la adaptación, Barcelona, Paidós.

Fecha de recepción: 19/06/2019.

Fecha de aceptación: 25/07/2019. 